PII: S0045-6535(99)00062-4

\title{
DEGRADATION PATHWAYS OF PCBS UPON UV IRRADIATION IN HEXANE
}

\author{
Xiu-Sheng Miao, Shao-Gang Chu, Xiao-Bai Xu* \\ Research Center for Eco-Environmental Sciences, \\ Chinese Academy of Sciences, Beijing, 100085, China
}

(Received in Germany 6 November 1998; accepted 19 February 1999)

\begin{abstract}
The photodegradations of eight individual PCB congeners $(5,31,52,77,87,126,138,169)$ in hexane have been investigated employing a mercury lamp. All degradation reactions of the above mentioned PCB congeners are of the pseudo first order. The principal products of PCB decomposition are the less chlorinated biphenyls. and no PCB-solvent adducts are found. Symmetrical and coplanar PCB congeners show lower photoreactivities. The reactivities of the chlorine atoms at various positions of PCB rings are generally in the order: ortho $>$ meta $>$ para. Photodechlorinations occur mainly on the more substituted rings. when the numbers of chlorine atoms on the two phenyl rings are unequal. During photodegradation, some coplanar PCB congeners are formed, which make the TEQ of solutions to decrease slowly or even to increase.

(01999 Elsevier Science Ltd. All rights reserved

INTRODUCTION

Polychlorinated biphenyls (PCBs) are a group of compounds produced commercially by direct chlorination of biphenyl. PCBs found application in a wide variety of industrial uses including heating-transfer, flame retardant, organic diluents, and dielectric fluids, because of their physicochemical properties [1].

In a 50-year period, approximately 1.4 billion pounds of PCBs were produced. Such extensite application of these compounds has resulted in widespread contamination [2]. It has been estimated that several hundred million pounds have been released to the environment[3].

The importance of understanding the environmental degradation pathways for PCBs has prompted a variety of studies on chemical reactivity, physical transport, and biotransformation in water, sediments, and soils. Under ultraviolet light irradiation, PCBs were significantly decomposed [4-7], but quantitative data
\end{abstract}

* to whom all correspondence should be addressed 
useful for environmental assessment are either lacking or are in conflict; information on transformation pathways is notably incomplete. The study on photodegradation mechanisms of PCBs upon UV irradiation is important to elucidate the long-term temporal trends of PCBs, including the frequently observed variations in the gas chromatographic patterns of PCBs in environmentally samples.

This study was designed to get detailed informations about the photodestruction mechanisms of PCBs. We initiated a systematic study of the photodegradation in hexane of a variety of individual PCB congeners. including the representative of Aroclor mixtures and highly toxic coplanar PCB congeners. This approach would make feasible the identification of the dechlorination products of these congeners.

Conventionally, it has been thought that $\mathrm{PCB}$ concentrations in the top $100 \mu \mathrm{m}$ layer of the natural water might be up to twenty times or even greater $\left(10^{6}\right)$ than those in the bulk water [8].

To identify different PCB congeners produced during the photodegradation of individual PCB congeners, a new GC retention index system was used coupled with GC-MS $[9,10]$.

\section{EXPERIMENTAL SECTION}

\section{Reagents}

2,3-dichlorobiphenyl (congener 5), 2,4',5-trichlorobiphenyl (congener 31), 3,3' .4.4' tetrachlorobiphenyl (congener 77), 2,2',3,4.5' -pentachlorobiphenyl (congener 87) and 2.2' $3.4 .4^{\prime}$ ',5' hexachlorobiphenyl (congener 138) were purchased from Analabs, Inc.). 3,3', 4,4', 5-Pentachlorobiphenyl

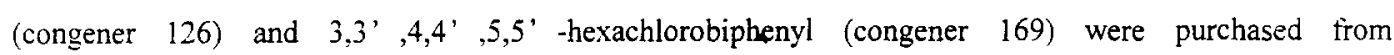
AccuStandard Inc.. Aroclor 1242 and Aroclor 1254 were purchased from Supelco Company. 2,2' ,5,5' Tetrachlorobiphenyl (congener 52) was synthesized and purified in our laboratory ( $>99.9 \%$ pure by capillary GC column). Hexane of analytical grade was redistilled in an all glass system. The numbering system suggested by IUPAC was used throughout this study [11].

\section{Irradiations}

$10 \mathrm{~mL}$ hexane solutions of different individual PCB congeners were photolyzed in quartz tubes sealed with glass stoppers (photoreactor made by the Institute of Photographic Chemistry, the Chinese Academy of Sciences) at $25^{\circ} \mathrm{C}$. The distances between a $300 \mathrm{~W}$ mercury lamp and quartz tubes were $8 \mathrm{~cm}$. The initial concentrations of different $\mathrm{PCB}$ congeners ranged from $0.1 \mathrm{ppm}$ to $1.7 \mathrm{ppm}$. Kinetic measurements were based on 5-9 time points, in which $\ln [C t]$ was regressed with time $t$ to give the slope $K_{p}$. 


\section{Analytical Methods}

Irradiated samples were analyzed using a Varian 3740 gas chromatograph fitted with a $\mathrm{Ni}^{63}$ electron capture detector ( ECD ). A SE-54 ( $40 \mathrm{~m} \times 0.25 \mathrm{~mm}$ i.d., J \& W Scientific Inc. ) column was used with nitrogen carrier gas. The sample injector and detector were maintained at 300 and $350^{\circ} \mathrm{C}$. respectively; the column underwent a temperature profile of $50^{\circ} \mathrm{C}$ for $2 \mathrm{~min}$, ramp to $280^{\circ} \mathrm{C}$ at a rate of $4^{\circ} \mathrm{C} / \mathrm{min}$.

The identification results were confirmed by GC-MS (VG TRIO 2000) which used the same SE-54 capillary column and temperature program as GC analysis.

Quantification of degradation products was calculated basing on the peak areas with their respective response factors of PCB congeners on the ECD [12].

\section{RESULTS AND DISCUSSION}

It was found that photodegradation of all individual $\mathrm{PCB}$ congeners is of the pseudo first order. which is in agreement with the photodegradations of PCB congener 66,101 110,118 and 138 using simulated suniight and diethylamine [13], and the photochemistry behavior of 4-chlorobiphenyl in water [14]. Table 1 displays the half-lives of photodegradation reactions for these irradiated PCB congeners. It is indicated in the table that both coplanar PCB congeners (congener 77, 126 and 169) and symmetrical congener 52 showed lower photoreactivities. Calculated LUMO energies were found to be lowest for the coplanar congeners within a homolog series [15], and this is consistent with our data of their half-lives observed. With the extended conjugation between two phenyl rings in a planar configuration, an increase in electron affinity and thus the longer half-lives of photodegradations were observed. Similar result has been reported that congener 52 underwent little degradation in petroleum ether upon gamma irradiation, and the relative amount of orthodechlorinated products is small relative to meta-dechlorinated products. It was explained that ortho chlorines involved in a 2,5 (or 3,6 ) substitution pattern would apparently reduce dechlorination at those positions $(5$ ). Comparing the half-life of congener 5 with those of congener 31 and congener 52 etc., it was found that highly chlorinated species did not lose their chlorine atoms more easily[4]. The photoreactivity of PCB congeners is predominantly affected by the positions of substituted chlorines.

Table 1. Half-lives of PCB congeners upon exposure to UV irradiation in hexane

\begin{tabular}{cccc}
\hline congener no. & half-lives(sec) & congener no. & half-lives(sec) \\
\hline 5 & $1.9 \pm 1.7$ & 31 & $90 \pm 9.1$ \\
52 & $8.3 \times 10^{2} \pm 83$ & 77 & $8.8 \times 10^{2} \pm 80$ \\
87 & $52 \pm 5.7$ & 126 & $6.2 \times 10^{2} \pm 63$ \\
138 & $18 \pm 1.6$ & 169 & $7.7 \times 10^{2} \pm 78$ \\
\hline
\end{tabular}

The main photoproducts were less chlorinated biphenyls. Fig. 1 shows PCB congeners and their 
photoproducts profile at different irradiation times. However, some mono-chlorobenzene and pdichlorobenzene were also detected during the photolysis, which are in agreement with the results of the photolysis of congener 52 with xenon lamp [16]. So it may be suggested that photodegradation of PCBs proceed through successive dechlorinations of the biphenyl nucleus accompanied by cleavage of inter-ring bonds to form chlorobenzenes both with xenon lamp and mercury lamp. Contrary to the results reported by Koshioka et al. for photodegradation of decachlorobiphenyl [17], PCB-solvent adducts were not detected by GC or GC-MS in our experiment, although the detection limit of GC-ECD has been achieved up to 4ppt, and with a GC-MS scan range of $40-500 \mathrm{M} / \mathrm{z}$. So replacement reactions to produce PCB-solvent adducts may not be a significant process for the photodegradation of PCBs under our experimental conditions.

A
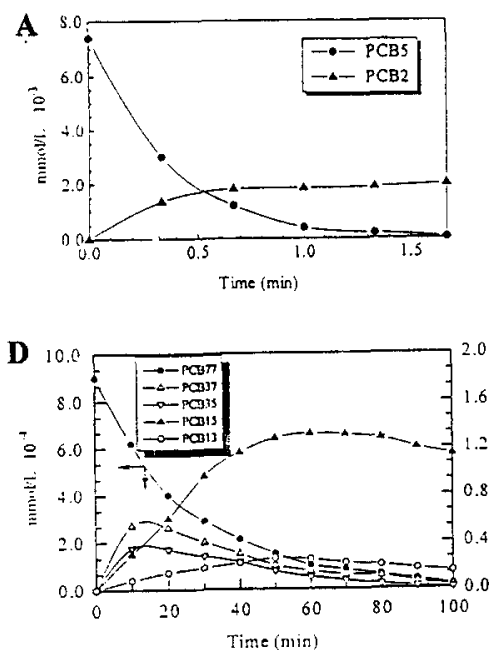

G
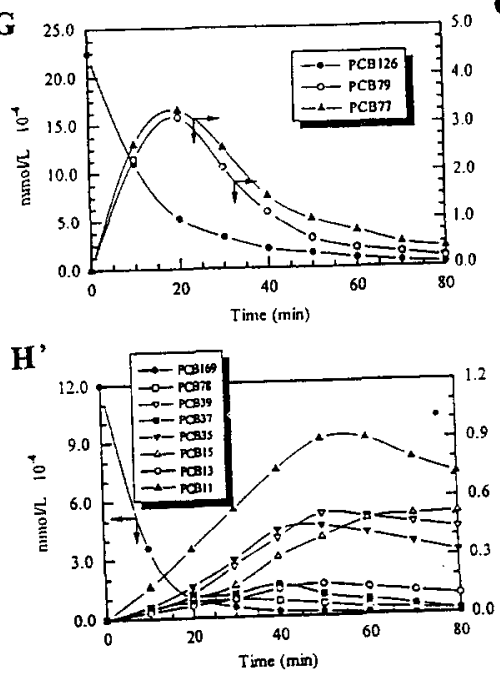
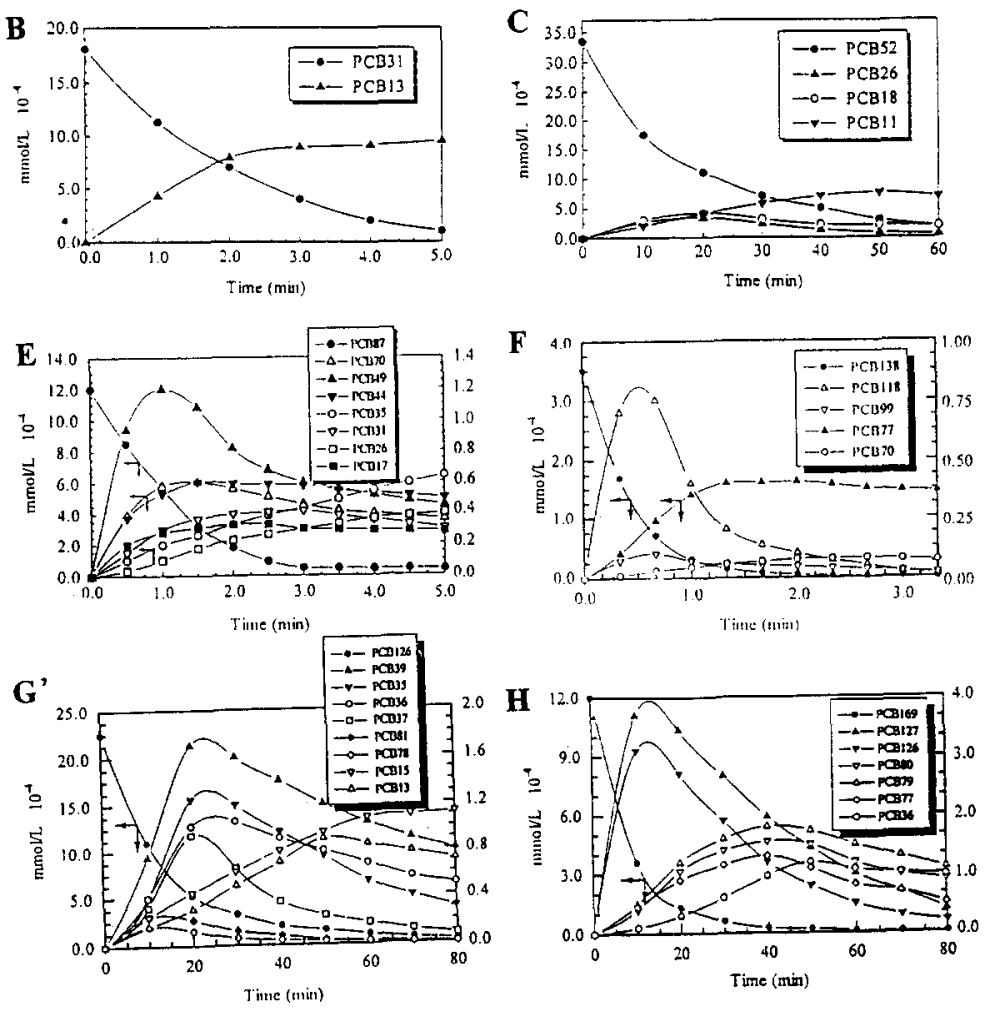

Fig. 1 The concentrations of PCB congeners and their photoproducts at different times
A. congener 5
$B$. congener 31
C. congener 52
D. congener 77
E. congener 87

F. congener 138 G.G'. congener 126 H, H'. congener 169 
The unsymmetrical substituted biphenyls, congener 31,87 and 126 , usually photo-degraded by dechlorination on the more substituted ring. For example, there are same number of chlorines on each rings in the detected degradation products of congener 87 during the photodegradation, which are congener $44\left(2,2^{\prime}, 3,5^{\prime}\right.$-tetrachlorobiphenyl), congener $49\left(2,2^{\prime}, 4,5^{\prime}\right.$-tetrachloro-biphenyl) and congener $70\left(2,3^{\prime}, 4^{\prime}, 5\right.$-tetrachlorobiphenyl). The possible product congener 55 (2,3,3' ,4-tetrachlorobipheyl) arising from the lose of an ortho chlorine from the less substituted ring was not detected, although the chlorine atoms at the ortho positions of PCB congeners usually show much higher elimination efficiency than the chlorine atoms at meta and para positions [4]. So the presence of reactive ortho substitutent in the less substituted ring of congener 87 does not favor dechlorination of that ring. Similar results also can be found from the photodegradation of congener 126. The amounts of degradation products. congener 77 and congener $79\left(3,3^{\prime}, 4,5^{\prime}\right.$-tetrachlorobiphenyl) are in much higher concentration than congener 78 (3,3', 4,5-tetrachlorobiphenyl) and congener 81 (3,4,4',5-tetrachlorobiphenyl). The above mentioned results are similar to that observed in the gamma radiolytic degradation of PCBs [18].

Also, the results shown in Fig. 1 are in agreement with those described in previous reports, that the ortho chlorines are lost preferentially when ortho and other positions are substituted by chlorines [19, 20]. Most of the products formed through ortho dechlorination were observed during the photodegradation of congener 5, 31, 87 and 138 which bear reactive ortho chiorine atoms. Ruzo et al. on the basis of the photolysis of tetrachlorobiphenyls in neutral solution, concluded that the marked elimination of the ortho chlorine atom was caused by both electronic and steric effects of the phenyl rings. especially the latter [21, 22].

It is an exception that ortho chlorines of congener 52 were not lost preferentially (shown in Fig. 1), this unusual result might be explained by the specific molecular structure of congener $\mathbf{5 2}$. The bond lengths of carbons with ortho-chlorines and with meta-chlorines are $1.746(8)$ and $1.746(9) \AA$. . respectively, which are identical [23].

It can be seen from Fig. 1 that the formation of meta-dechlorination products would be favored only after the loss of the ortho chlorines products. In the photodegradation of congener 77 , the relative amount of meta-dechlorination products, congener $37\left(3,4,4^{\prime}\right.$-trichlorobiphenyl) is large relative to para-dechlorination products, congener $35\left(3,3^{\prime}, 4\right.$-trichlorobiphenyl). Contrary to the results of a previous study [24], both congener 35 and congener 11 were formed during the photolysis of congener 77 in hexane. The same results can be found both for coplanar congeners and ortho-chlorinated congeners in our experiment. However, the photodegradation of congener 169 shows the different result, which may be accounted for the symmetrical structure of congener 127 (3,3',4,5,5' -pentachlorobiphenyl), namely the formation of symmetrical dechlorination products is favored. It may be suggested that in general the reactivities of the chlorines at various positions of phenyl rings decrease in the order: ortho > meta > para, which is not in good agreement with the result of PCBs degradations upon gamma irradiation. The reactivity of chlorines at various positions 
upon gamma irradiation decrease in the order: ortho > para > meta [18]. In our experiments, paradechlorinations are also observed, and such a degradation pathway is barely observed upon UV irradiation of PCB containing other chlorine substituents in addition to para chlorine atoms[25].

The regioselective reductive dechlorination pathways of PCBs upon UV irradiation is of special environmental significance and could help environmental chemists in understanding the frequently observed variations in the gas chromatographic patterns of PCBs in environmentally collected samples. Hence, the proposed major photodechlorination pathways of some congeners are shown in Fig. 2, numbers underlined in which represent IUPAC no. of different PCB congeners.

The acute toxicities of PCBs are relatively low for most animal models. However, some specific PCB congeners that are structurally related to 2,3,7,8-tetrachlorodibenzodioxin (TCDD) have toxicological properties similar to TCDD [26]. These coplanar congeners, namely congener 77, 126 and 169, along with their abundant toxic monoortho-substituted analogs congener 105 (2,3,3',4,4' -pentachlorobiphenyl). congener $118\left(2,3^{\prime}, 4,4^{\prime}, 5\right.$-pentachloro-biphenyl), congener 156 (2,3,3',4,4',5-hexachloro-biphenyl), congener $157\left(2,3.3^{\prime}, 4,4^{\prime}, 5^{\prime}\right.$ 'hexachlorobiphenyl), congener $167\left(2,3^{\prime}, 4,4^{\prime}, 5,5\right.$ ' -hexachlorobiphen: 1$)$ and congener $189\left(2,3,3^{\prime}, 4,4^{\prime}, 5,5^{\prime}\right.$-heptachlorobiphenyl) are even considered a great threat to terrestrial and marine mammals than polychlorinated dibenzodioxins (PCDD) and dibenzofurans (PCDF) [27,28].

Currently, PCBs regulatory standards are derived from results of animal studies with commercial PCB mixtures such as Aroclor 1260. However, the composition of PCBs present in food products or environmental samples does not resemble commercial mixtures and risk assessment should take into account the contributions of individual PCBs in these mixtures. The toxic equivalency factor (TEF) approach now being used as an interim measure for risk assessment of PCDDs and PCDFs has been discussed as a model for congener-specific risk management of PCBs. Ahlborg et al. have given the detailed study on TEF for dioxinlike PCBs [29]. Due to the fact that dioxin-like compounds normally exist in biological samples as complex mixtures of congeners, the concept of toxic equivalents (TEQs) has been introduced to simplify risk assessment and regulatory control. Several studies have utilized the TEF approach for calculating total TEQs contributed by PCBs, PCDDs and PCDFs in various biotic extracts [30, 31]. Safe et al. also studied TEF approach for risk assessment of combustion by-products [32]. 

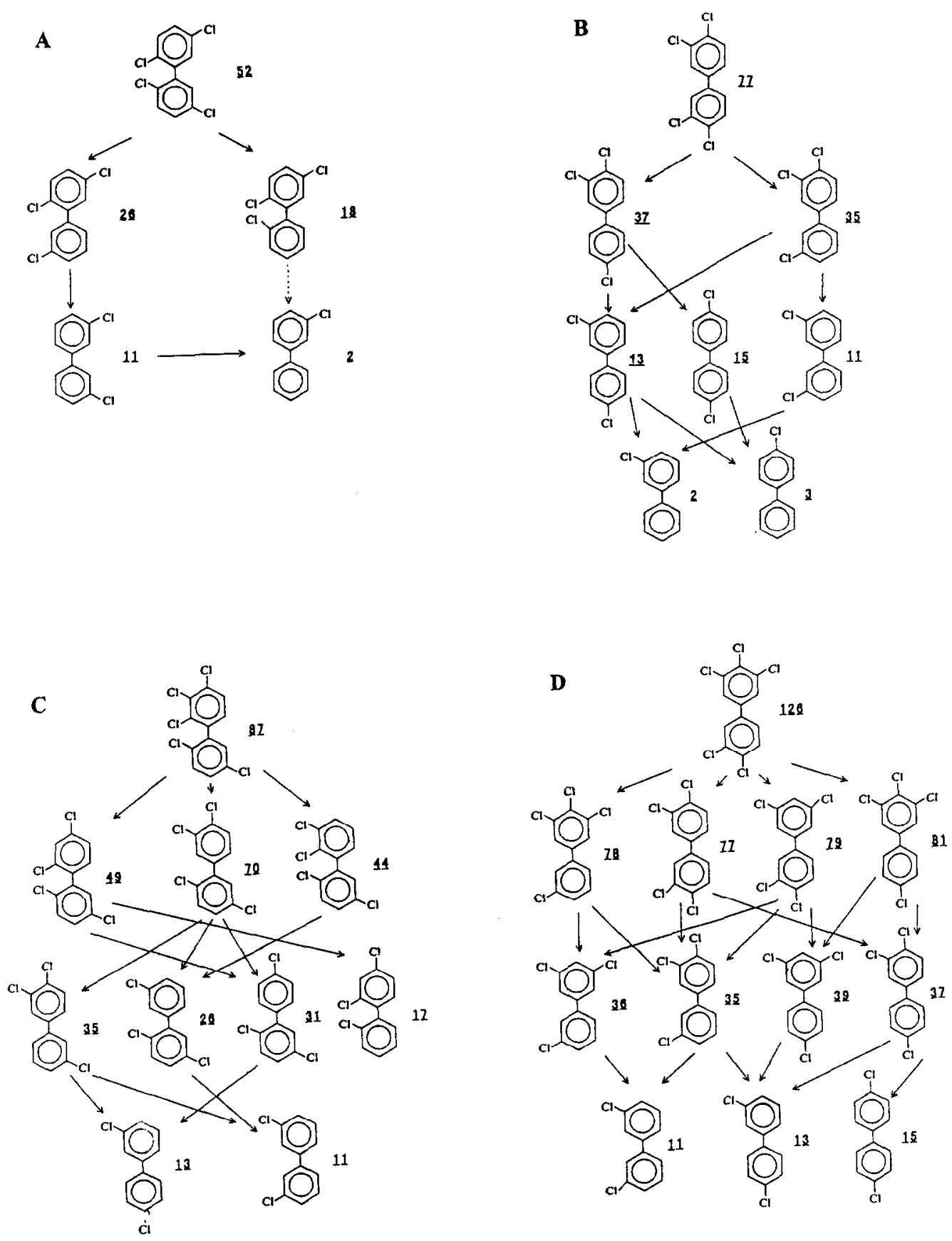

Fig.2 Proposed major photodechlorination pathways of PCB congeners
A. congener52
B. congener 77
C. congener87
D. congener 126
E. congener138
F. congener 169 

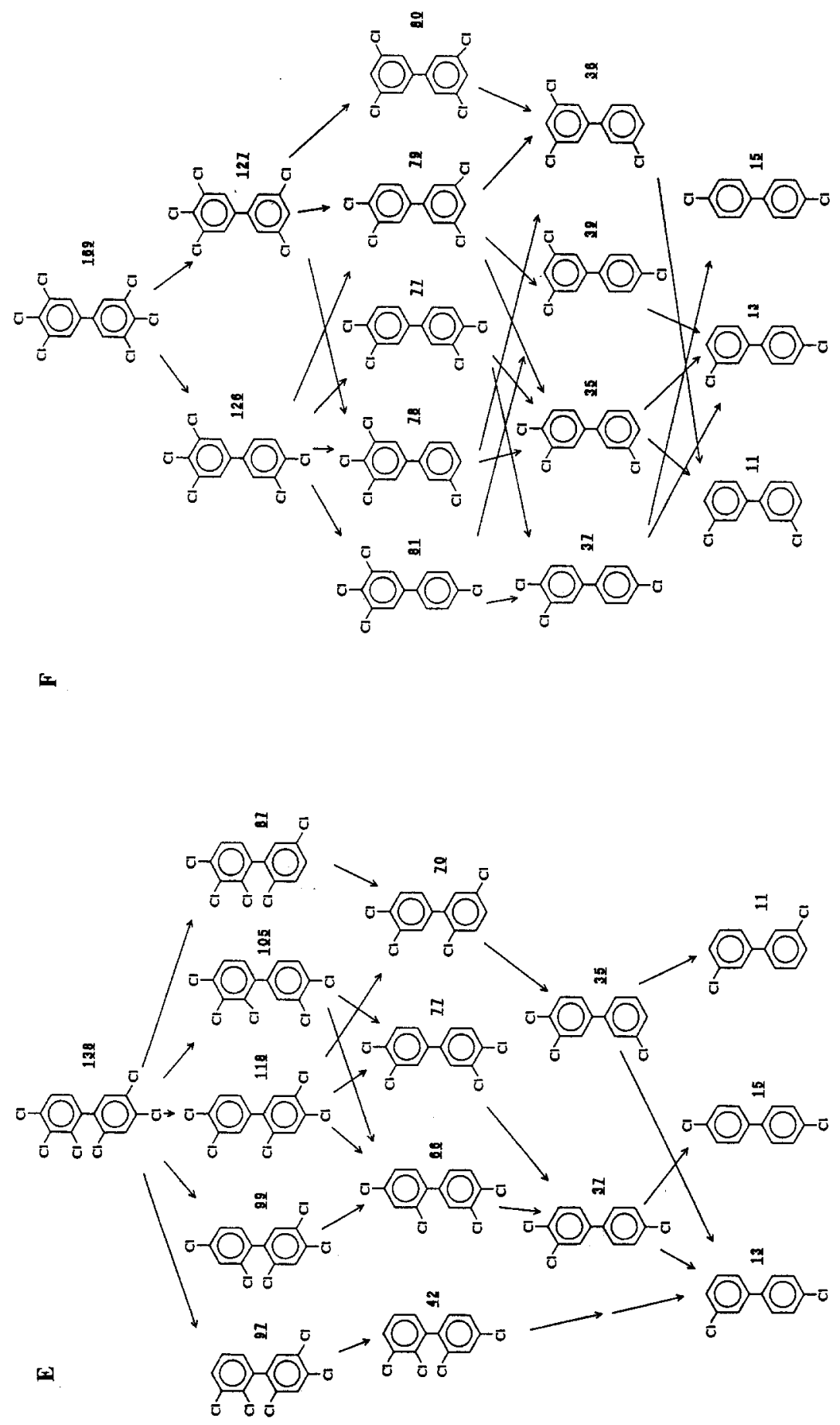
With the considerable degradation of congener 138 upon UV irradiation, the toxic coplanar congener 77 is largely produced through the loss of ortho chlorine atoms of the more substituted ring. Contributed from the low photoreactivity of congener 77 , the TEQs increased rapidly with the degradation of the precursor congener 138, as shown in Fig. 3. Also, being accounted for the formation of coplanar congener photoproducts, the TEQs of solutions for congener 126 and 169 do not decrease as quickly as the disappearance of these precursors. It should be pointed that TEQs of treated solutions should be considered besides of the disappearance of the precursors during study of treatment methods for PCBs.

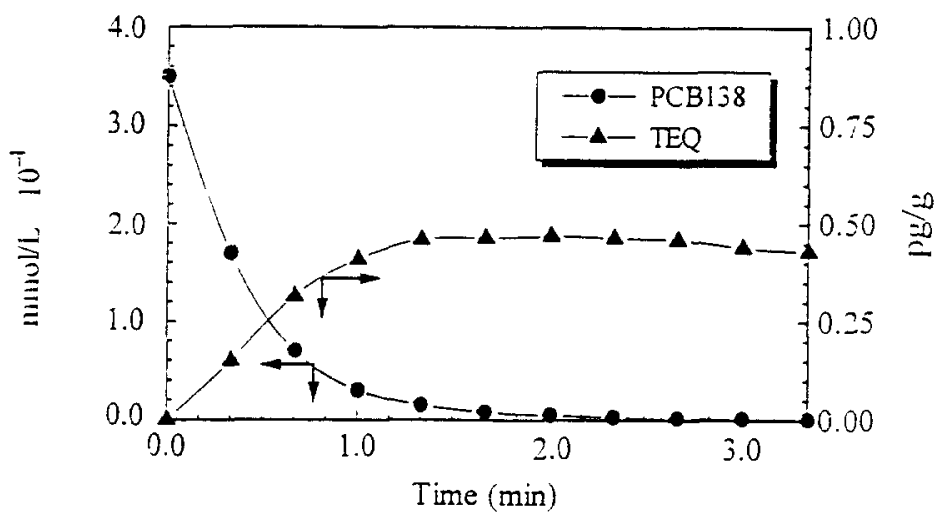

Fig. 3 TEQs of photolyzed solutions of $2,2,3,4,4^{\prime}, 5^{\prime}$ congener 138 at different irradiation times

Based on the observed degradation pathways of PCBs (shown in Fig. 2), it is suggested that toxicologically important coplanar congeners might be generated from some potential precursors. congener $118,128,138,153,170,180,194,195$ and 196, some of which are very abundant in commercial PCB mixtures, for example, $5.0 \%$ congener 138 and $8.2 \%$ congener 153 are in Aroclor 1260 , respectively. So it is very important to investigate the photodegradation pathways of coplanar PCB congeners and potential precursors of toxic PCB congeners.

\section{ACKNOWLEDGMENT}

This research was jointly supported by the Chinese Academy of Sciences and the National Vatural Foundation of China. Thanks are also due to Ms shan Fu for preparing the manuscript. 


\section{REFERENCES}

[1] O. Hutzinger, S. Safe, V. Zitko, The chemistry of PCBs,CRC Press: Cleveland, OH (1974).

[2] E. H. Buckley, Accumulation of airborne polychlorinated biphenyls in foliage, Science 216, 520-522 (1982).

[3] D. G. Ackerman, L. L. Scinto, P. S. Bakshi, R. G. Delumyea, R. J. Johnson, G. Richard, A. M. Takata, E. M. Sworzyn, Destruction and disposal of PCBs by thermal and nonthermal methods, p. 2-6. Noyes Data, Park Ridge, New Jersey (1983).

[4] N. J. Bunce, Y. Kumar, An assessment of the impact of solar degradation of polychlorinated biphenyls in the aquatic environment, Chemosphere 2, 155-164 (1978).

[5] N. J. Bunce, Y. Kumar, L. Ravanal, S. Safe, Photochemistry of chlorinated biphenyls in isooctane solution, J. Chem. Soc. Perkin 2, 880-884 (1978).

[6] L. - W. Chang, C. S. Giam, Photodegradation of tetrachlorobiphenyls in water and hexane, Acta Scientiae circumstantiae 12, 242-248 (1992).

[7] F. Lepine, S. Milot. N. Vincent, Formation of toxic PCB congeners and PCBsolvent adducts in a sunlight irradiated cyclohexane solution of Aroclor 1254 , Bull. Environ. Contam. Toxicol. 48, 152-156 (1992).

[8] E. B. Ofstad, G. Lunde, 2nd International Symposium on Aquatic Pollutions, Amsterdam, September, (1977)

[9] S.-G. Chu, X.-S. Miao, X.-B. Xu, Retention index system for identification of polychlorinated biphenyl congeners in gas chromatographic analysis, J. Chromatgr. A724, 392-397 (1996).

[10] X.-S. Miao, S.-G. Chu, X.-B. Xu, Identification of photoproducts for PCB congeners by the new retention index system, Chinese J. Chromatgr. 15, 465-469 (1997).

[11] K. Ballschmiter, M. Zell, Analysis of polychlorinated biphenyl(PCB) by glass capillary gas chromatography, Fresenius' Z Anal. Chem. 302, 20-31 (1980).

[12] E. D. Mullin, C. M. Pochini, S. McCrindle, M. Romkes, L. M. Safe, High-resolution PCB analysis: synthesis and chromatographic properties of all 209 PCB congeners, Environ. Sci. Technol. 18, 468-476 (1984).

[13] Y. Lin, G. Gupta, J. Baker, Photodegradation of Aroclor 1254 using simulated sunlight and various sensitizers, Chemosphere 31, 3323-3344 (1996).

[14] T. Moore, R. M. Pagni, Unusual photochemistry of 4-chlorobiphenyl in water, J. Org. Chem. 52, 770-773 (1987).

[15] J. Greaves, E. Harvey, W. G. MacIntyre, Correlation between electron capture negative 
chemical ionization mass spetrometric fragmentation and calculated internal energies for polychlorinated biphenyls, J. Am. Soc. Mass Spectrom. 5, 44-52 (1994).

[16] X.-S. Miao, S.-G. Chu, X.-B. Xu, Photodegradation of 2,2',5,5'-tetrachlorobiphenyl in hexane, Bull. Environ. Contam. Toxicol. 56, 571-574 (1996).

[17] M. Koshioka, J. Kanazawa, H. Lizuka, T. Murai, Photodegradation of decachlorobiphenyl, Bull. Environ. Contam. Toxicol. 38, 409-415 (1987).

[18] F. Lepine, R. Masse, Degradation pathways of PCB upon gamma irradiation, Environ. Health perspect. 89, 183-187 (1990).

[19] N. J. Bunce, Photodechlorination of PCBs: current status, Chemosphere 11, 701-714 (1982).

[20] T. Nishiwaki, T. Shinoda, K. Anda, M. Hida, The dechlorination of polychlorinated biphenyls by UV-irradiation. VIII. Reaction of 2,3- and 3,4-dichlorobiphenyl in a :propanol solution, Bull. Chem. Soc. Jpn. 55, 3565-3568 (1982).

[21] L. O. Ruzo, M. J. Zabic, R. D. Schuetz, Photochemistry of bioactive compounds: photoproducts and kinetics of polychlorinated biphenyls, J. Agric. Food Chem. 22. 199-202 (1974).

[22] L. O. Ruzo, M. J. Zabic, R. D. Schuetz, Photochemistry of bioactive compounds photochemical processes of polychlorinated biphenyls, J. Am. Chem. Soc. 96, 3809-3813 (1974).

[23] X.-S. Miao, S.-G. Chu, X.-B. Xu, X.-L. Jin, 2,2',5,5'-Tetrachlorobiphenyl (PCB 52), Acta Cryst C52, 2582-2583 (1996).

[24] L. O. Ruzo, M. J. Zabik, R. D. Schuetz, Polychlorinated biphenyls: photolysis of 3,4,3',4'-tetrachlorobphenyl and 4,4'-dichlorobiphenyl in solution, Bull. Environ. Contam. Toxicol. 8, 217-218 (1972).

[25] M. J. Zabik, The photochemistry of PCBs. P. 141-186. In: Itri FMD and Kamrin MA (ed) PCBs: Human and Environmental Hazards, Butter worth, Boston (1983).

[26] S. Safe, S. Bandiera, T. Sawyer, L. Robertson, L. Safe, A. Parkinson, P. E. Thomas, D.E. Ryan, L. M. Reik, W. Levin, M. A. Denomme, T. Fujita, PCBs: Structure-function relationships and mechanism of action, Environ. Health Perspect. 60, 47-56 (1985).

[27] N. Kannan, S. Tanabe, R. Tatsukawa, Toxic potential of non-ortho and mono-ortho coplanar PCBs in commercial PCB preparation: " $2,3,7,8-\mathrm{T}_{4} \mathrm{CDD}$ toxicity equivalence factors approach" , Bull. Environ. Contam. Toxicol. 41, 267-276 (1988).

[28] N. Kannan, S. Tanabe, T. Okamoto, R. Tatsukawa, D. J. H. Phillips, Polychlorinated biphenyls (PCBs) in sediments in Hong Kong: a congener-specific approach to the study of coplanar PCBs in aquatic ecosystems, Environ. Pollut. 62, 223-235 (1989). 
1650

[29] U. G. Ahlborg, G. C. Becking, L. S. Birnbaum, A. Brouwer, H. J. G. M. Derks, M Feeley, G. Golor, A. Hanberg, J. C. Larsen, A. K. D. Leim, S. H. Safe, C. Schlatter, F Waern, H. Younes, E. Yrjanheikki, Toxic equivalency factors for dioxin-like PCBs Chemosphere 28, 1049-1067 (1994).

[30] S. Safe, Polychlorinated biphenyls(PCBs), dibenzo-p-dioxins(PCDDs) dibenzofuran (PCDFs), and related compounds: environmental and mechanistic consideration which support the development of toxic equivalency factors(TEFs), Crit. Rev. Toxicol. 21 , $51-88(1990)$.

[31] S. Tanabe, N. Kannan, A. Subramanian, S. Watanabe, R. Tatsukawa, Highly toxic coplanar PCBs: occurrence, source, persistency and toxic implication to wildlife and humans. Environ Pollution. 47, 147 (1987).

[32] S. Safe, L. V. Rodriguez, L. S. Goldstein, Toxic equivalency factor approach for risk assessment of combustion byproducts, Toxicol. Environ. Chem. 49, 181-191 (1995). 